\title{
Reinterpretación del relieve histórico emeritense de M. Agrippa a partir de un nuevo fragmento
}

\author{
antonio M. Poveda Navarro *
}

\begin{abstract}
RESUMEN
La reciente identificación de un fragmento escultórico con la representación de un toro preparado ornamentalmente para su sacrificio, que se encontraba depositado entre los fondos del Museo Nacional de Arte

Romano de Mérida, ha permitido relacionar la pieza con el conocido relieve de $M$. Agrippa en acción de sacrificar, de esta forma se puede completar el relieve en su parte derecha según se le contemple frontalmente. $A$ partir de este nuevo dato se revisa la visión interpretativa de la obra, que encuentra ahora la verificación de que se trata de un sacrificio de los típicos destinados al culto imperial romano, donde frecuentemente aparece una alta figura del estado o de la familia del emperador, que se encarga de sacrificar una víctima animal muy simbólica y recurrente, que generalmente, como en este caso, es un toro. Además, se
\end{abstract}

\section{ABSTRACT}

The recent identification of a piece of a sculpture with the representation of an ornamentally prepared bull for its sacrifice, which was among the collection of the National Museum of Roman Art has made possible to relate the piece with the famous $M$. Agripa's relief in a sacrificing position, in this way we can complete the relief in its right part if we look at it directly. Taken this, the interpretative vision of the work of art is revised, thus obtaining verification that it is a typical sacrifice destined to the Roman imperial cult, where very frequently we find either a high ranking official or someone belonging to the emperor's family, who is in charge of offering up the animal victim, a highly symbolic and recurring sacrifice, which, like in the present case generally involves the ritual killing of a a bull. Besides there remains the possibility of it being a

* Universidad de Alicante. 
plantea la posibilidad de que el relieve formase parte del ara Providentiae de Augusto, altar monumental de Mérida conocido a través de su aparición en el reverso de algunas emisiones monetales de Tiberio. part of the ara Providentiae of Augustus, which is a monumental altar of Merida known by some coins of the Tiberian period.

El azar ha querido que después de que iniciáramos una investigación sobre el relieve histórico romano con escenas de sacrificio, recibiéramos una invitación para participar en un ciclo de conferencias que dentro de los Cursos de Verano de la Universidad Nacional de Educación a Distancia ${ }^{1}$, se debían desarrollar en el Museo Nacional de Arte Romano de Mérida, en el verano del año 1996. El tema propuesto era "Poder e Imagen en Roma", en este mismo sentido planteamos presentar el estado de nuestra investigación sobre "La imagen del toro en la representación sacrificial en Roma". Para nosotros, y aunque todavía no sabíamos nada de la existencia de un nuevo fragmento donde se apreciaba parcialmente un toro, debía formar parte de la misma el conocido y excepcional relieve del Museo emeritense donde aparece representado M. Agrippa, en plena acción de realizar una libación previa al inminente sacrificio que debía producirse posteriormente, aunque hasta ese momento no existían indicios de qué animal o animales serían sacrificados. Sin embargo, en nuestra conferencia presentamos la propuesta de que la víctima sería un toro que debía dirigirse hacia la izquierda, es decir, en dirección a la figura de $\mathrm{M}$. Agrippa y el centro del relieve.

Después de nuestra intervención recibímos la noticia de que entre los fondos del Museo existía un fragmento del relieve de un toro, que habría aparecido en el mismo lugar donde se hallaron los otros restos del relieve de Agrippa. La amabilidad de T. Nogales, conservadora de dicho centro, nos permitió conocer toda la información sobre la nueva pieza escultórica, de modo que la pudimos observar directamente e incluso emplazarla momentáneamente en la exposición museística, junto a las otras partes conservadas del mencionado relieve histórico. En ese momento pudimos verificar que sus características estilísticas y morfológicas eran semejantes a las del nuevo fragmento de mármol con la representación de un bóvido. Por tanto, entendimos que éste completaba iconográfica e ideológicamente el citado relieve, y que ante esta evidencia era pertinente presentar su estudio pues de esta manera se podría plantear una nueva interpretación de la composición representada.

' Curso Poder e imagen en Roma, dirigido por P. Fernández Uriel y T. Nogales Basarrate, en Mérida, del 1 al 5 de julio, dentro de los VII Cursos de Verano de la UNED,1996. 
El nuevo fragmento que hemos identificado apareció en la misma área de Mérida que los otros restos marmóreos del mismo relieve histórico, es decir en la zona de Pancaliente, hacia el norte de la ciudad, junto al río Guadiana, donde de forma fortuita, en el año 1934, se recuperaron treinta-y-nueve fragmentos, en un lugar de vertedero donde existía una cloaca romana que en parte estaba construida con materiales reutilizados, fragmentos de clípeos monumentales, cariátides y fragmentos de relieves como el del toro y los demás conocidos del altar de Agrippa $^{2}$. El conjunto de piezas llegó al Museo Nacional de Mérida en el año 1943.

La reutilización de estas piezas de mármol de calidad en una cloaca ha condicionado que se les hallase desplazadas del lugar donde fueron emplazadas originalmente, en monumentos arquitectónicos con un importante programa ornamental, de modo que no sabemos exactamente donde se ubicaban. Sin embargo, el haber servido de soporte a la iconografía más querida del arte oficial, aúlico, dedicado al culto imperial, como es la de los sacrificios a cuyo tema pertenece nuestro relieve emeritense, nos permite suponer cuál fue su posible emplazamiento primitivo. Éste debió ser en la zona de la calle Sagasta, en las proximidades del Templo de Diana, por ello hay un buen número de investigadores que han pensado que formarían parte del pórtico monumental de ese lugar del Foro municipal de Augusta Emerita ${ }^{3}$ (figs. 1 y 2), conocido como «Foro del mármol» y datado entre el final de la época de Claudio y el inicio de Nerón, sin embargo, como luego se argumentará, es más probable que formase parte de un altar de época de Tiberio.

\footnotetext{
2 J. Alvarez Saenz de Buruaga: "Museo Arqueológico de Mérida. El Museo en el año 1943", Memorias de los Museos Arqueológicos Provinciales, Madrid, 1943, p. 46, láms. V-IX. A. GaRciA Y Bellido, Esculturas Romanas de España y Portugal, Madrid, 1949, pp. 416-419, láms. 298-299, n. . 418 A-F. M. FloRIANI SOUARCIAPINO: "Ipotesi di lavoro sul gruppo di sculture da Pan Caliente", en Actas del Simposio Internacional Conmemorativo del Bimilenario de Mérida (1975). Mérida, 1976, pp. 55-62, láms. 23-30; Idem: en Homenaje a Sáenz de Buruaga, Mérida, 1982, pp. 40-43, figs. 5-6 y 9-10. W. TrillmiCH: "Eine historisches Relief in mit Darstellung des M. Agrippa beim Opfer", Madrider Mitteilungen, 27, 1986, pp. 276-304. W. TRILLMICH et alii: Hispania Antiqua. Denkmäler der Römerzeit, Mainz am Rhein, 1993, pp. 290-291, lám. 61, b. M. BENDALA GALÁN, R.M. " DuRÁn CABELLO: "Catálogo", en AA.VV. La Ciudad Hispanorromana, Barcelona, 1993, p. 290. T. Nogales Basarrate: "Relleu d'una escena de sacrifici amb la representació de M. Agripa", en AA.VV.: La mirada de Roma. Retrats romans dels museus de Mérida, Toulouse i Tarragona, Barcelona, 1995, p. 206; Idem: "Relieve de Agripa", en AA.VV.: Hispania Romana. Desde Tierra de Conquista a Provincia del Imperio, Madrid, 1997, p. 354.

3 W. TAILLMICH; op. cit. nota 2. W. Trillmich et alii: op. cit. nota 2, p. 290. M. BENDALA GALÁN, R.M. Durán Cabello: op. cit. nota 2, p. 290. T. Nogales Basarate: “Relleu d'una escena...", op. cit. nota 2, p. 206; Idem: «Relieve de Agripa", op. cit. nota 2, p. 354.
} 
ANTONIO M. POVEDA NAVARRO

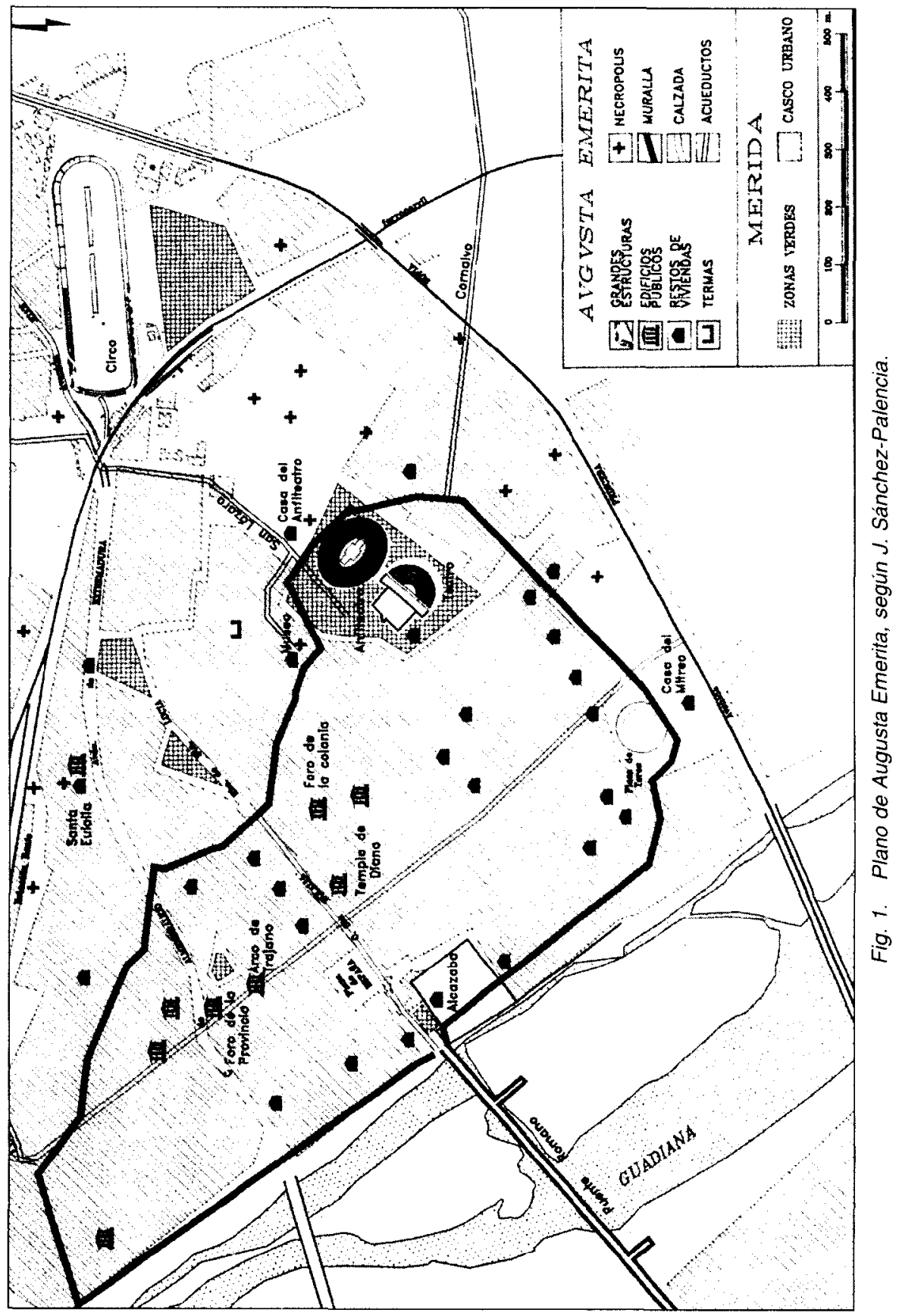


Reinterpretación del relieve histórico emeritense de M. Agrippa...

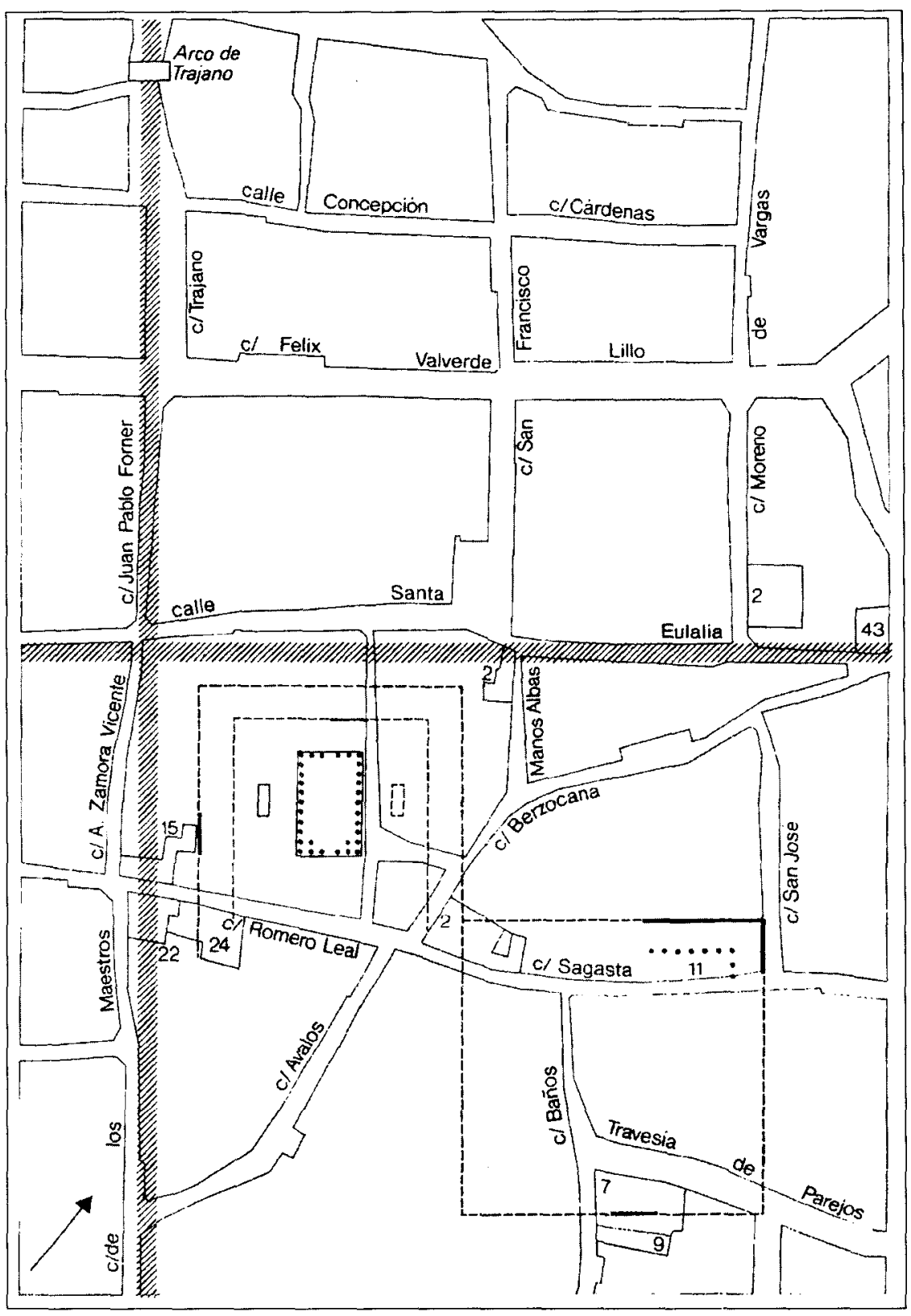

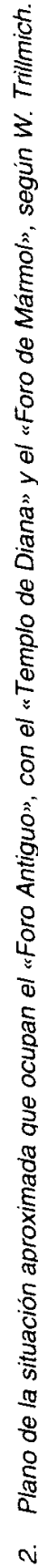

is 


\section{EL NUEVO FRAGMENTO}

La nueva pieza estaba entre los fondos depositados en los almacenes del Museo Nacional de Arte Romano de Mérida, su número de inventario es el 23.180. Se trata de un fragmento de mármol blanco de granos o cristales finos cuyas dimensiones son $35 \mathrm{~cm}$ de altura, $32 \mathrm{~cm}$ de longitud y $15 \mathrm{~cm}$ de grosor. La placa es de muy buena calidad y presenta líneas de fractura que no encajan con ninguna de las otras cinco piezas del mismo relieve, sin embargo, estudiando sus respectivas proporciones, estilo artístico, morfología y temática representada, no ofrece ninguna duda de su pertenencia a esta importante obra iconográfica del culto imperial en Mérida.

El fragmento muestra la representación en relieve de un toro que se dirige hacia la izquierda según se le contempla frontalmente (fig. 4). La figura del bóvido se conserva parcialmente pues solamente se aprecia su cuerpo en su mitad anterior hasta el cuello, faltándole la cabeza y las patas. El animal está ornamentado con los típicos elementos que simbolizan su preparación para desfilar en la pompa, en la procesión cívico-religiosa que le llevaría ante el ara junto a la que sería sacrificado. Es por ello que se observa sobre su cuerpo la característica dorsuale, banda finamente decorada con un capullo floral sobre el que se desarrollan tallos y rosetas cuyos pétalos oscilan en número, pues según los casos disponen de cinco, seis u ocho. Los bordes están representados por bordones de trazo sogueado. La disposición de la dorsuale se nos antoja atípicamente adelantada, pues aparece prácticamente sobre los hombros del toro, a poca distancia del cuello. Entre los muchos relieves con bóvidos preparados para su sacrificio ritual no encontramos por regla general esta situación, no obstante un posible paralelo se puede ver en algunos de los toros de uno de los frisos del templo de Apollo Sosiano, en Roma, fechado entre los años 20 y 17 a.C., y de una base de altar del Palazzo della Cancelleria, datado entre los años 30 y 50 d.C., ambas obras levantadas en Roma ${ }^{4}$. Quizás también se pueda relacionar con el relieve del altar de la apoteosis de Augusto, en uno de cuyos lados menores se observa otro taurus con una banda semejante y en parecida disposición, se trata de un monumento datado poco después del año 40 d.C., en época de Claudio, que se encuentra en el Museo Nazionale di Ravenna ${ }^{5}$.

Otro ornamento característico de la víctima taurina que realiza la procesión es la vitta, que normalmente es representada como una cinta de

4 R. Bianchi Bandinelli: Roma. L'Arte Romana nel centro del Potere, Milán, 1985, pp. 69-70.

5 H. KäHLER: Roma e l'arte imperiale, Milán, 1963, pp. 102-103. 


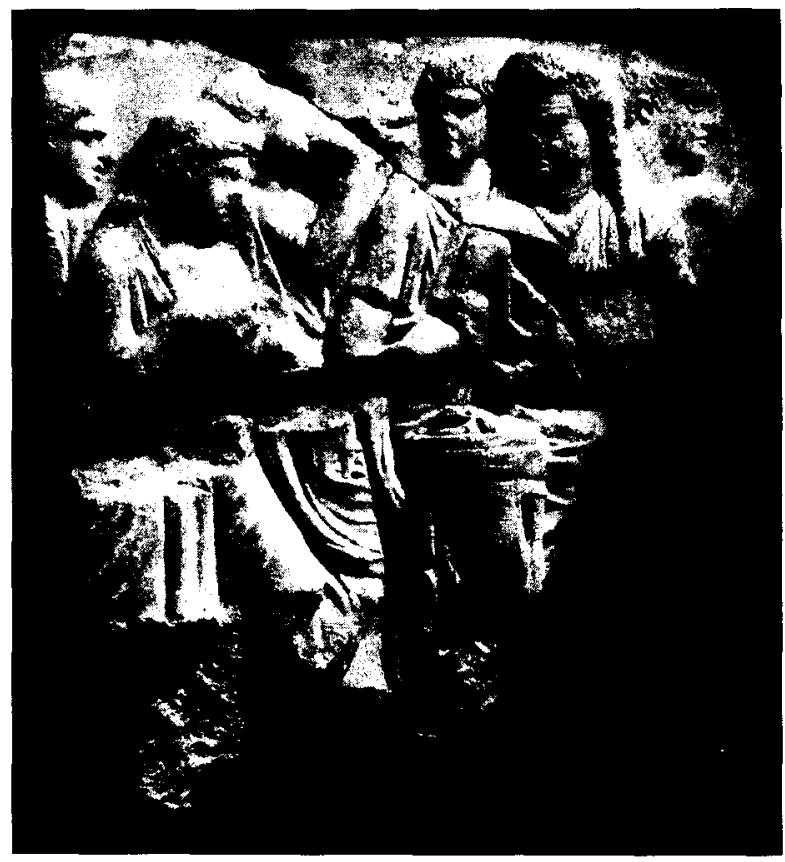

Fig. 3. Fragmento de relieve con M. Agrippa preparando un sacrificio (Foto DAl-Madrid, R125-96-16, Patterson).

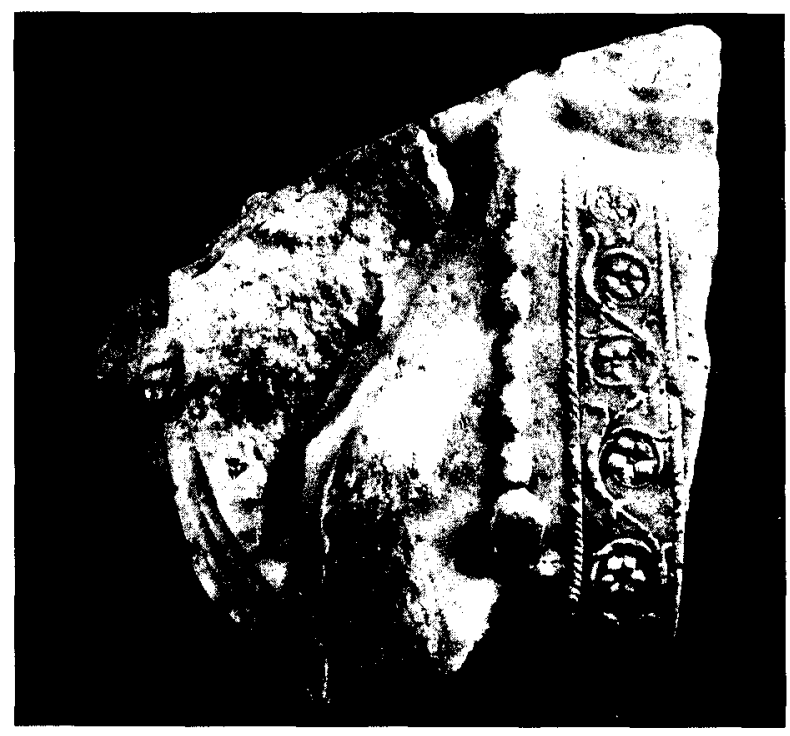

Fig. 4. Nuevo fragmento de relieve con toro ornamentado para su sacrificio (Foto DAl-Madrid, R123-96-4, Patterson). 
astrágalos en serie que en nuestro caso termina en una especie de capullo caliciforme idéntico al de la parte inferior de la dorsuale. Ambos elementos decorativos están exageradamente próximos, circunstancia que no encuentra paralelos en el arte de los relieves romanos. Las vittae suelen disponerse suspendidas entre las orejas y la cornamenta del toro, sin embargo, en la pieza emeritense aparece una de ellas, la que se corresponde con la que ornamentaría la parte izquierda de la testa del bóvido, que se sitúa colgando sobre el mismo cuello, por tanto algo desplazada del lugar donde se coloca habitualmente.

Todavía se observa otro detalle en el nuevo fragmento, en la zona pectoral del toro, delante de los pliegues que presenta, se puede contemplar la representación de cuatro dedos humanos que pertenecen a la mano del victimarius que sujeta las bridas del animal. Con toda seguridad es la mano izquierda del personaje de torso desnudo que aparece a la espalda y a la derecha de M. Agrippa, en el fragmento central del relieve donde está realizando una libatio y aparece togado y con velatio capitis y la corona cívica (fig. 3). En esta placa la escena tiene que ver por tanto con el momento inmediatamente previo al sacrificio del toro que es presentado por el citado victimarius encabezando la pompa que se acerca desde la derecha de Agrippa, que aparece acompañado por un primer camillus, muy probablemente el que llevaba el urceus o guttus, normalmente una hydria, que contenia el líquido para la libación, a continuación aparece un segundo camiIlus, un muchacho muy joven que como es típico presenta cabellos largos, que ofrece abierta la acerra para que Agrippa, que extiende su mano derecha, pueda recoger el incienso. Por detrás de ambos se observa al tibicen en plena acción de tañir su doble tibia, destacando que la de forma curva tiene terminación en cabeza de ofidio. Finalmente, a la izquierda de todo el grupo aparece conservado parcialmente un posible flamen, o en todo caso un magistrado, miembro de los amplissima sacerdotia, es decir, alguien que pertenecería al cuerpo de los más importantes colegios sacerdotales, como los pontífices, augures, etc ${ }^{6}$. Este personaje sacerdotal pudo estar acompañado todavía por otro más. Entre lo que se puede apreciar de su cuerpo destaca que viste una toga, probablemente la praetexta, poco habitual en estas escenas, pues en la parte que le cae verticalmente sobre la zona pectoral se distingue una terminación a modo de flecos, como los que creemos reconocer en la representación procesional de la cara norte del Ara Pacis, donde el tercer camillus presenta un gran paño ornamentado con bordes de flecos, que cuelga del antebrazo y mano que sostiene la

6 P. Zanker: Augusto e il Potere delle immagini, Turín, 1989, pp. 128-131. 
acerra. La acción ritual tiene lugar ante un foculus circular, de metal, quizá trípode, que sería portátil y que tiene un paralelo exacto en el representado entre la ornamentación de la acerra que porta ese mismo camillus del mencionado altar de Augusto en Roma ${ }^{7}$.

Otro de los fragmentos conservados, el correspondiente a la parte superior del flanco derecho, nos muestra parcialmente un lictor, del que apenas se conserva su cabeza y el hombro izquierdo sobre el que apoya su típica insignia, las fasces. Debido al espacio que todavia existe entre éste personaje y el victimarius, es muy probable que también compusieran la procesión cultual otro lictor y un individuo que nunca falta en estas ocasiones, el popa que portaría la letal hacha larga, la sicuris necesaria para el momento de la immolatio del toro mediante su degollamiento y abatimiento. Ambos personajes aparecerían por detrás de esta bestia, como es norma en este tipo de representaciones ${ }^{8}$. En cambio, ese mismo espacio no nos parece que permitiese la representación de una suovetaurilia, o en todo caso de otras hostes, por tanto, la única víctima que podía ocupar ese lugar sería un taurus, el que aquí presentamos.

Ambas escenas, la libatio y la pompa, se encuentran flanqueadas por dos arcos o altas puertas, que pueden corresponderse con el marco urbano y arquitectónico ante el que transcurren, que posiblemente sea el frente del foro emeritense y por tanto de sus vanos de ingreso, o también pudiera ser la puerta monumental con dos arcos que permitía acceder a la ciudad, pues este motivo arquitectónico fue un recurso muy usado por la colonia, como se desprende de su frecuente aparición en emisiones monetales de Mérida ${ }^{9}$.

En la parte superior del relieve, en una ancha franja, hay una serie de elementos decorativos propios del ambiente en el que debe producirse el sacrificio ritual. Se trata de guirnaldas compuestas por una gran variedad de frutas que entrelazan bucráneos con vittae, infulae, ramas de laurel,

M. TORELli: Typology and Structure of Roman Historical Reliefs, Ann Arbor, 1992, p. 45 ,

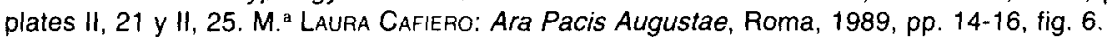

8 Para conocer suficientemente y con precisión quiénes eran y qué caracteristicas tenían los frecuentes participantes en las procesiones civico-religiosas, con las que se llevaban a las victimas animales ante el altar donde se sacrificaban, es imprescindible la lectura del profundo estudio realizado por S. TORTORELLA: el rilievi del Louvre con suovetaurile: un documento del culto imperiale", Ostraka, 1, 1992 (junio), 81-104.

9 A. BELTRÁN: "Los monumentos en las monedas hispano-romanas", Archivo Español de Arqueologia, XXVI, 1953, pp. 53-54, figs. 15-16; Idem: “Las monedas romanas de Mérdia. Su interpretación histórica", en Actas del Simposio Internacional Conmemorativo del Bimilenario de Mérida (16-20 de noviembre de 1975), Madrid, 1976, pp. 95 y 98-99, lám. XXXIA. L. VILLARONGA: Numismática Antigua de Hispania, Barcelona, 1979, p. 275, n. ${ }^{\circ} 1055$ y 1056. 
espigas de trigo y hydriae. La composición ornamental así formada está claramente inspirada en los modelos iconográficos utilizados en varios monumentos de Roma, los más próximos a los empleados en nuestro relieve se ven en el recinto interior del Ara Pacis de Augusto ${ }^{10}$, que desde su construcción , años 13-9 a.C., dejó establecido el paradigma de las imágenes a emplear en el arte de los relieves destinados a ilustrar los principales monumentos dedicados al culto imperial ${ }^{11}$.

Precisamente la aparición del friso de guirnaldas sobre una típica escena del relieve histórico como ocurre en la pieza de Mérida ya fue destacada hace tiempo, indicando que no es habitual que aparezcan ambos elementos combinados en un mismo relieve, así en el prototipo de este arte, la citada Ara Pacis, las guirnaldas están en el recinto interior y los relieves de procesión en la fachada exterior. No obstante hay algunos ejemplos excepcionales donde se conjugan los dos tipos iconográficos, es el caso del mausoleo de los Julios, en Saint-Rémy, Provenza, el altar de los Lares del Belvedere, el ara de C. Manlio o el gran relieve que estaba en el Laterano con la representación de un sacrificio realizado por un emperador divinizado ${ }^{12}$.

\section{UNA NUEVA VALORACIÓN DEL RELIEVE}

Para entender la naturaleza y el destino expositivo que tenía esta obra artística es necesario conocer su posible dimensión monumental. Hasta ahora, con los cinco fragmentos que se conocían del relieve, se había pensado que debía tener una longitud o anchura de unos siete pies romanos, es decir, sobre algo más de dos metros, sin embargo, con la inclusión del fragmento del toro y el estudio de las proporciones de los elementos del relieve, tratados por medios informáticos, y nuestra nueva propuesta (fig. 5) interpretativa, opinamos que pudo tener cerca de dos metros y setenta centímetros, por tanto nueve pies romanos. Un tamaño semejante nos indica que debió ocupar un lugar privilegiado en el área monumental de la ciudad de Mérida, donde las imágenes que existieran tuviesen la más adecuada difusión, pues el mensaje de la ideología del culto imperial así lo requería.

\footnotetext{
10 R. Bianchi Bandinelli: Roma. L'arte..., op. cit. nota 4, pp. 187-188. P. Zanker: Roma e il Potere..., op. cit. nota 6, p. 127, fig. 96.

11 R. BIANCHI BandinelLi, H.J. Eggers, F. CoARelli: Arte Romana e Commercio artistico oltre $i$ confini, Roma, 1965, p.19. Tonio HölsCher: Il linguaggio dell'Arte Romana, Turín, 1993, p. 46.

12 M. Floriani Souarciapino: “lpotesi di lavoro...", op. cit., nota 2, p. 61.
} 


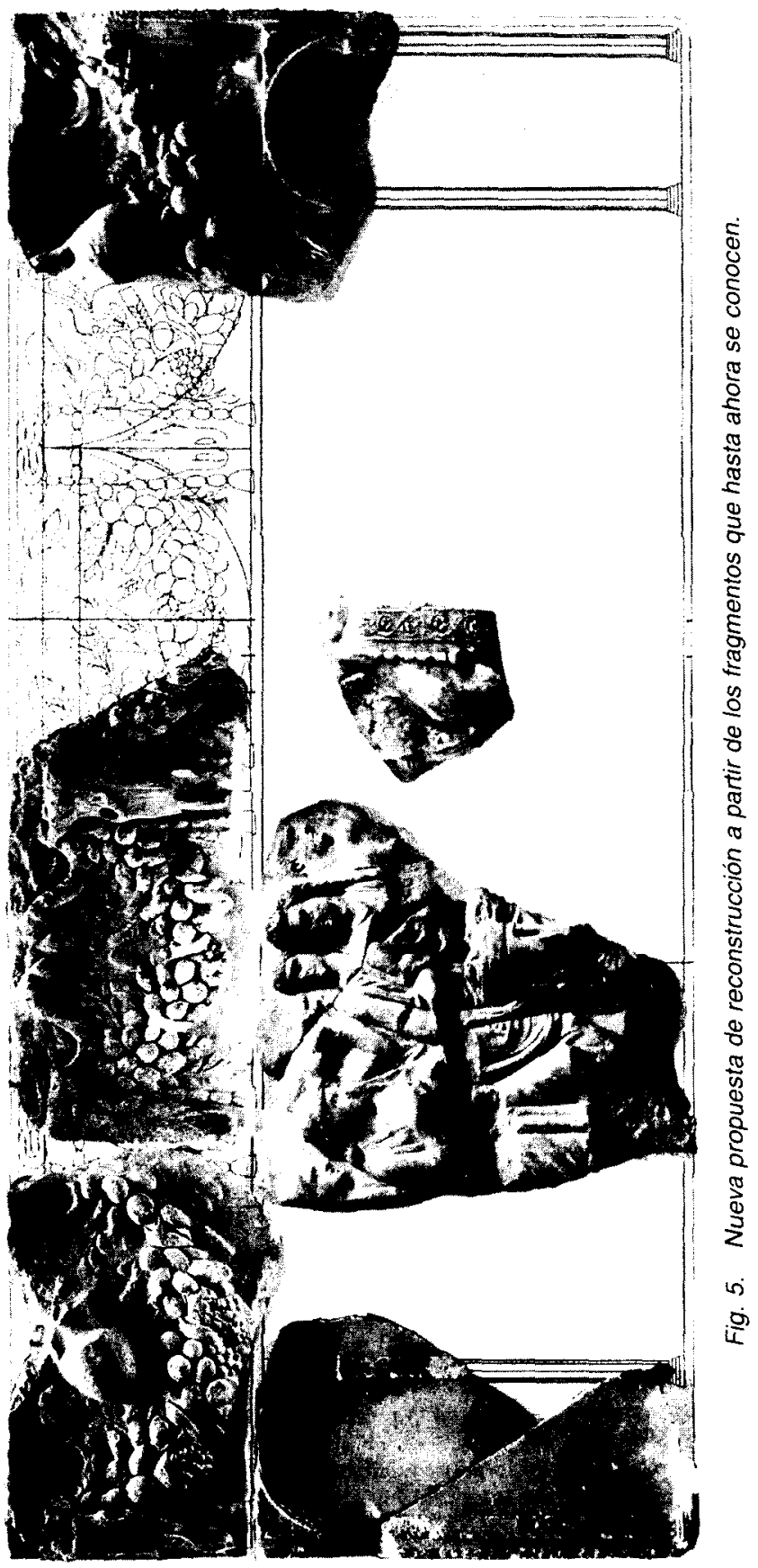


El relieve emeritense es el mejor exponente del arte romano culto de Hispania, del género denominado relieve histórico cuyo fin es promocionar el culto imperial. En esta ocasión la obra nos muestra dos momentos relacionados con un sacrificio destinado al mismo. En la parte izquierda se representa a M.Agrippa realizando una libación ritual, e inmediatamente a su derecha se desarrolla la procesión cívica y cultual con la que llega la víctima, un toro engalanado para la ocasión. Ambas escenas convergen en el centro de la placa.

Los temas tratados, la modalidad artística empleada, la iconografía asumida, el fin ideológico que persigue, nos llevan a coincidir con otros investigadores ${ }^{13}$ en la idea de pensar que estamos ante un excepcional relieve perteneciente a un altar monumental, que tendría sus mejores prototipos en la propia Roma, en los altares de la Pax Augusta, la Pietas Augusta o la Providentia Agusta.

En estas aras se desea rendir homenaje a Augusto a través de sus distintas virtudes, para de esta forma enriquecer el culto imperial a él dedicado. En el altar emeritense se pudo propiciar también un culto a su recuerdo y reconocimiento, pero de lo que no cabe duda es que el único relieve conocido de su programa decorativo representa un claro homenaje a Agrippa, tratado como el patrono fundador de la ciudad, como su planificador y evergeta, sin olvidar tampoco la fuerte relación personal y familiar que tenía con Augusto. Todos estos hechos pudieron dar lugar a que fuese contemplado como providencial para la vida de la colonia y que se entendiese que compartía con Augusto su Providentia, cuya veneración en su ara de Roma fue perpetuada por emisiones monetales, como los ases de Tiberio de su serie divus Augustus pater, que en su reverso muestran la representación del ara Providentiae Augustae (fig. 6). Este fenómeno de reconocimiento y difusión mediante la numismática fue bastante normal, como ilustran bien otras acuñaciones que mostraban en su reverso la representación del ara Pacis y el ara Pietatis.

Teniendo en cuenta esta serie de datos y sobre todo la probada existencia del culto imperial en Mérida ${ }^{14}$, que ha sido igualmente recogido y

13 M. Floriani Squarciapino: "lpotesi di lavoro...", op. cit. nota 2, p. 62. T. Nogales BASARRATE: “Relleu d'una escena...", op. cit. nota 2, p. 206; ldem: "Relieve de Agripa", op. cit. nota 2, p. 354.

14 R. ETIENne: Le culte imperial dans la Peninsule Iberique d'Auguste a Dioclétien, París, 1958, pp. 220-221. D. FishwICK: The imperial cult in the Latin west, vol. 1.1, Leyden, 1987, pp. 180-183. J.S. Richardson: Hispania y los Romanos, Historia de España, II, Barcelona, 1998, pp. 153-154. 


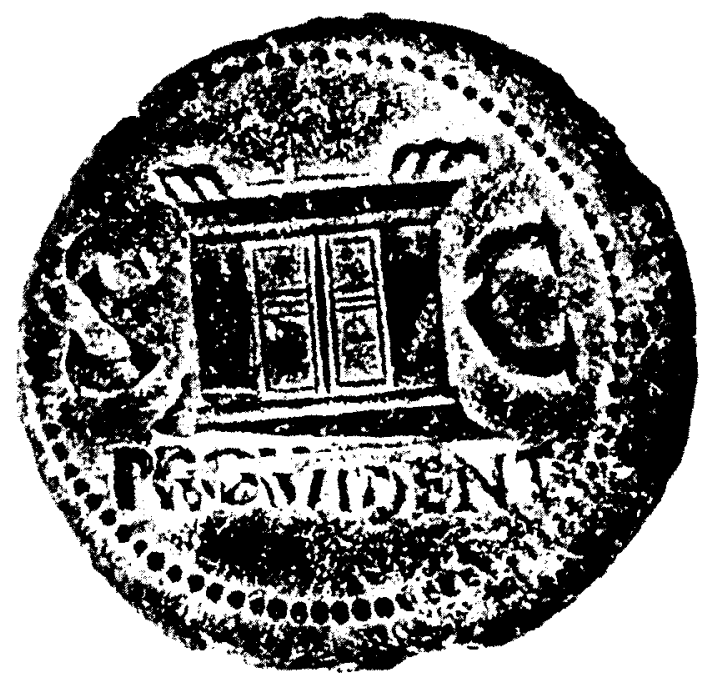

Fig. 6. Reverso de moneda de Roma con el ara Providentiae. (Foto de M. Torelli).

perpetuado por sus emisiones monetales de época de Tiberio ${ }^{15}$, donde aparecen representados tanto el templo como el altar (figs. 7-10) erigidos a tal fin, creemos muy probable que precisamente la moneda que muestra en el reverso la representación de un ara con la indicación escrita de Augusta Providentia, es la prueba de que a este altar monumental habria podido pertenecer el relieve de Agrippa.

Quizá un indicio que apoye esta idea sea que la procedencia de sus diversos fragmentos y otras piezas escultóricas se viene aceptando ${ }^{16}$ que sería la zona situada ante el foro municipal, en las proximidades del Templo de Diana, que precisamente era el destinado al culto imperial, de Augusto probablemente, es decir para la divinización imperial, objetivo que era el mismo que tenia el ara Providentiae de Mérida y su relieve de Agrippa.

Si aceptamos esta sugerente propuesta tendriamos que revisar también la datación que hasta ahora se le ha asignado al mismo, ya que la investigación en general, basándose en elementos estilísticos y ciertos indicios de la actividad edilicia, ha defendido su inclusión en el arte de la etapa julio-

15 A. Beltran: "Los monumentos en las monedas...", op. cit, nota 9, pp. 54-55, figs. 19-22; ldem: "Las monedas romanas...", op. cit nota 9, pp. 97, 102-103, lám. XXXII, E-F. L. VILLARONGA: Numismática Antigua..., op. cit. nota 9, pp. 273-275, n. ${ }^{\circ} .1057-1058$.

16 Ver nota 3. 

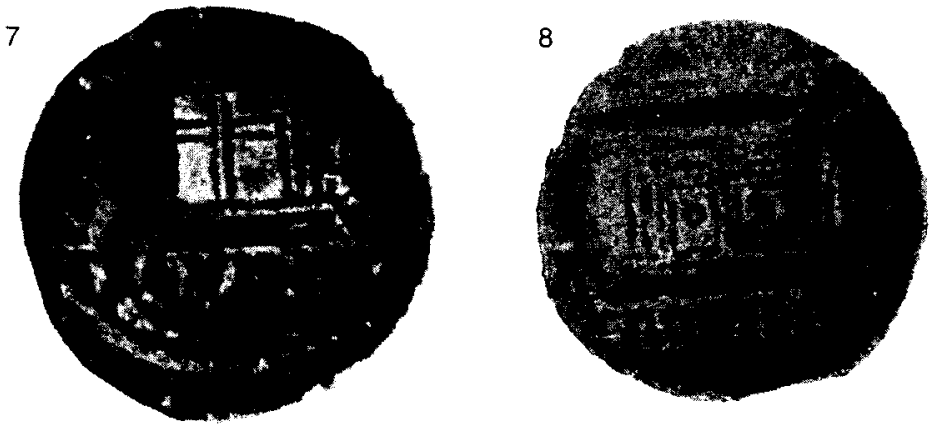

Figs. 7 y 8. Reversos de monedas de Mérida con el ara Providentiae. (Fotos de A. Beltrán, Seminario de Numismática de Zaragoza).
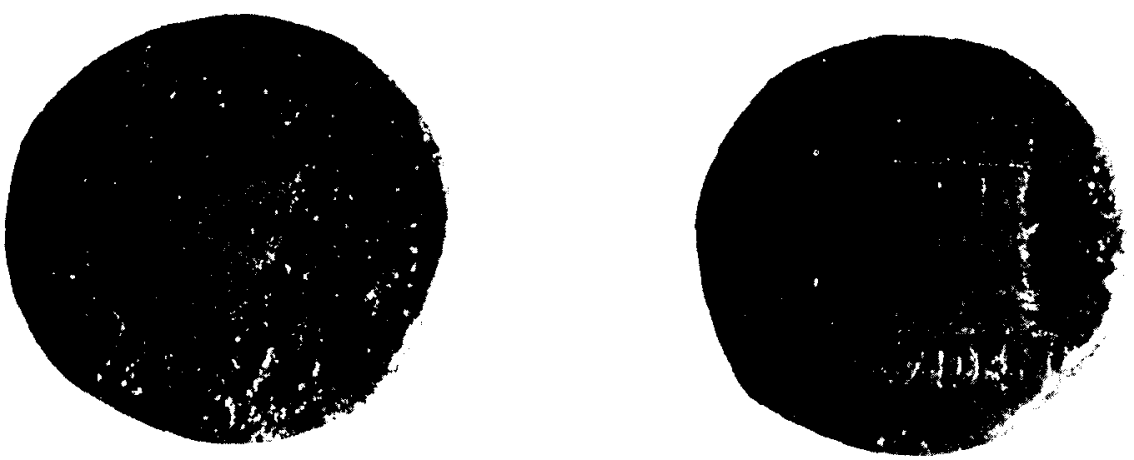

Fig. 9. Anverso y reverso de moneda de Mérida con busto de Augusto y el ara Providentiae (Fotos de J. M. Álvarez, MNAR de Mérida).
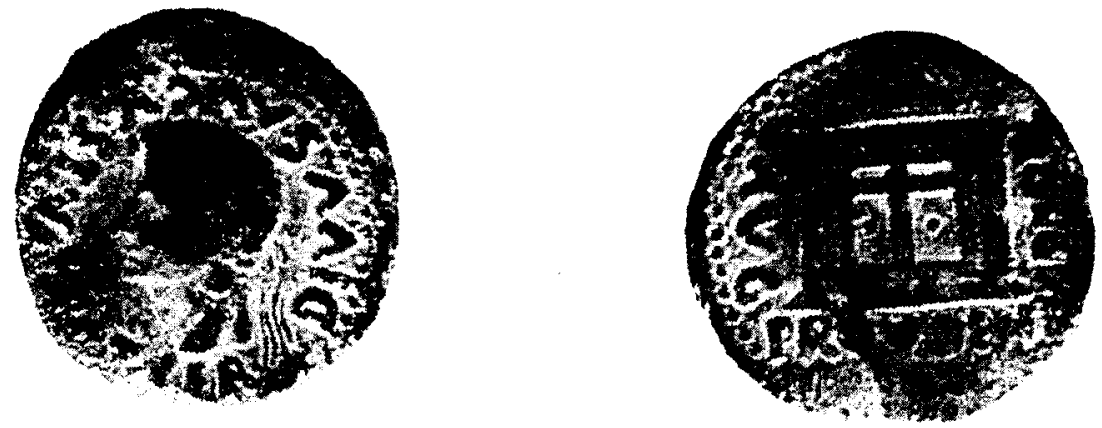

Fig. 10. Anverso y reverso de moneda de Mérida con busto de Augusto y el ara Providentiae (Fotos de L. Villaronga). 
claudia 17 o más concretamente de época de Claudio ${ }^{18}$, sin embargo, la aparición de la mencionada ara en emisiones monetales de época de Tiberio nos lleva a plantear que su cronología sería al menos tiberiana, lo que por otro lado no entra en contradicción con las características del estilo artístico del relieve, pues las fases de Tiberio y Claudio no presentan en este sentido diferencias apreciables.

Gracias a las citadas acuñaciones numismáticas todavía podemos establecer un paralelismo más entre las aras de Roma y la de Mérida. Cuando estos monumentos del culto imperial eran construidos e inaugurados no contaban con sistemas de cierre en sus vanos de ingreso, sin embargo, pocos años después aparecen dotados de puertas de clausura. Así vemos como en emisiones monetales de Roma y de Mérida aparecen sus respectivas arae Providentiae con portones de cierre, curiosamente esto ocurre en ambos casos ya en época de Tiberio como delatan sus monedas. De igual modo, el ara Pacis presenta iguales puertas en monedas de Nerón y de Domiciano, fenómeno que también se observa en las monedas de Adriano ilustradas en su reverso con el ara Pietatis ${ }^{19}$.

Todavía podemos encontrar algún dato del altar de la Providencia de Augusto en Roma que nos acerque a su relación con la de Mérida y nos aclare el motivo de su implantación en esta colonia.

Gracias a recientes hallazgos epigráficos ${ }^{20}$, como dos nuevos fragmentos de los Acta Arvalium o el texto del senatus consultum de Cn. Pison padre, encontrado en la Bética, se ha podido localizar el lugar de ubicación del altar en Roma, en el llamado Campus Agrippae ${ }^{21}$, en una posición simétrica respecto al Ara Pacis, situada en el contiguo Campus Martius,

17 M. ${ }^{\text {a }}$ Floriani Souarciapino: "Ipotesi di lavoro...", op. cit. nota 2, p. 62.

18 W. TrILlMiCh: “Eine historisches...", op. cit. nota 2. W. TrLLLMICH et alii: Hispania Antiqua..., op. cit. nota 2. M. Bendala Galán, R.M. D Durán Cabello: "Catálogo", op. cit. nota 2. T. Nogales BasarRate: "Relleu d'una escena...", op. cit. nota 2; Idem: "Relieve de Agripa", op. cit. nota 2.

19 M. Torelli: Typology and Structure..., op. cit. nota 7, plates II, 7-8, III, 5 y 12. M. LAURA Cafiero: Ara Pacis..., op. cit. nota 7, pp. 24-25. A. Beltrán: “Los monumentos...», op. cit. nota 9 , figs. 21-22; Idem: "Las monedas romanas...", op. cit. nota 9, lám. XXXII, E. L. VILLARONGA: Numismática Antigua.., op. cit. nota 9, n. ${ }^{\circ} 1058$.

20 J. SCHEID-H. BROISE: "Deux nouveaux fragments des actes des frères arvales", MEFRA, XCll, 1980, pp. 215 ss. P. Herz: “Die Arvalakten des Jahres 38 n. Chr.", BJ, CLXXXI, 1981, pp. 89 ss. W. Eck: "Das s.c. des Cn. Pisone patre und seine Publikation in der Baetica», Cahiers Glotz, 4, 1993, pp. 189-208. W. Eck, A. Caballos, F. Fefinandez: Das senatus consultum des Cn. Pisone patre, Münich, 1996; ldem: «El senatus consultum de Cn. Pisone Patre», en Hispania Romana. Desde tierra de conquista a provincia del Imperio, Madrid, 1997, pp. 215-221. A. CABALLOS, W. ECK, F. Fernandez: El Senadoconsulto de Gneo Pisón padre, Sevilla, 1996.

21 S.B. Platner, T. Ashby: A topographical dictionary of ancient Rome, Oxtord, 1929, p. 90. F. CoArelli: /l Campo Marzio. I. Dalle origini alla fine della Repubblica, Roma, 1997, pp. 5, 12 y 552 , fig. 140 . 
pues el Ara Providentiae quedaba situada frente a ella, al otro lado de la via Flaminia. De este modo, ambos altares encontraban una evidente relación topográfica que completaba a la ideológica ${ }^{22}$.

Anteriormente ya hemos mencionado que ciertas emisiones monetales recogen la citada ara entre sus figuras representadas. En Roma, a partir del año 14 d.C., se acuñan algunas de esas monedas en sus series de bronce con el objeto de conmemorar la consecratio de Augusto. Son piezas numismáticas que en el anverso muestran la cabeza radiada del emperador divinizado y la leyenda Divus Augustus pater, mientras que el reverso, en el caso de los dupondios, suele estar ilustrado con diversos monumentos del mayor significado simbólico en lo que respecta a la ideología augustea, empleada para celebrar los aspectos públicos de la vida de Augusto, especialmente aquellos que tuviesen una estrecha relación con la consecratio y que permitieran poner en evidencia los méritos político-religiosos del difunto y su reconocimiento por el estado, cuyo máximo exponente es la concesión de la apoteosis. Por su parte, los ases presentan símbolos que se asocian con las formas "privadas" y familiares de la apoteosis de Augusto. Son aquellos que sirven de auténtica expresión de la consecratio del divus Augustus, especialmente los que invocan a los promotores de la apoteosis, es decir, a Livia, que aparece como una personificación femenina, probablemente del tipo Pietas, y a Tiberio, presente a través de la representación del ara Providentiae Augustae, que en el decreto de la consecratio habría sido votada junto a alguna estatua de Pietas, de modo que se celebrarían ambas virtudes imperiales. La estatua aludiría al amor filial relacionado con el padre divinizado por sus adoptados Tiberio y Livia, y el altar, que es lo que aqui más nos interesa, a la providentia de Augusto respecto a la adopción de Livia y especialmente de Tiberio, pues con él el difunto príncipe aseguraba la sucesión al trono. Este era el principal objetivo de la virtud imperial celebrada en el altar ${ }^{23}$.

Los motivos que como vemos intervienen en su fundación y su posterior evolución y desarrollo histórico, además de las características que explican el significado de la virtud que le da nombre, han sido perfectamente recogidos en varios trabajos fundamentales ${ }^{24}$, que son los que nos permiten entender el fundamento y el objetivo ideológico del altar de Mérida, pues es una exacta traslación del significado, y posiblemente también de la morfología, del erigido

22 M. TORelli: «Topografia e lconologia. Arco di Portogallo, Ara Pacis, Ara Providentiae, Templum Solis», Ostraka, I,1, 1992 (junio), pp. 109-110.

23 M. TORELLI: “Topografia e Iconologia...", op. cit. nota 22, p. 109.

24 M. TORELlI: Typology and Structure..., op. cit. nota 7, pp. 64 ss.; Idem: «Topografia e Iconologia...", op. cit. nota 22, pp. 109 ss. J.P. MARTIN: Providentia deorum, Roma, 1982 
en Roma. De modo que estamos ante una prueba más de la perfecta imitatio de los programas constructivos e iconográficos que realiza la colonia de Augusta Emerita respectos de los de aquélla. La razón ha sido bien explicada y argumentada y tiene que ver con la idea de que la ciudad fue concebida con una fuerte carga propagandística e ideológica, pues debía convertirse en el auténtico símbolo del papel de Roma y del emperador ${ }^{25}$. Por ello, a partir de la fundación de Mérida y la actuación de M. Agrippa, en el año 25 a.C., la configuración urbana, las acuñaciones monetales, los monumentos, los puentes, la escultura, etc..., tienen como principal misión reflejar esa idea de reproducir la Urbs del Tiber en el territorio más occidental del Imperio, en la capital de la Lusitania. En este sentido, debemos mencionar y destacar las importantes aportaciones que recientemente han puesto de relieve que el Forum Augustum de Roma fue el espejo de Mérida, como se comprueba en una serie de esculturas halladas e identificadas en la zona de su foro central, y sobre todo en el denominado Templo de Diana y el Pórtico del Foro ${ }^{26}$. Pues se ha podido reconocer hasta un grupo escultórico de Eneas con Ascanio y Anquises e incluso a través de una inscripción, la presencia del culto al Pater Indiges, forma que era utilizada para designar al propio Eneas ${ }^{27}$.

Por todo ello, pensamos que no es en absoluto descabellado plantear que el relieve emeritense de $\mathrm{M}$. Agrippa pertenezca al ara Providentiae levantada por Tiberio, en el contexto propagandístico empleado para crear una réplica monumental e iconográfica de Roma en Mérida. Igualmente, podria plantearse que la "marmorización» que conoció la ciudad de Augusta Emerita habría comenzado ya en época tiberiana sin tener que esperar al periodo de Claudio, momento en el que tradicionalmente se ha pensado para el inicio del empleo masivo del mármol ${ }^{28}$.

25 M. Bendala Galán, José M. Álvarez Martinez: "Semblanza de Augusta Emerita", Extremadura Arqueológica, IV, 1995, pp. 179-190.

${ }_{26}$ W. Trillmich: "Reflejos del programa estatuario del Forum Augustum en Mérida", en Actas de la II Reunión sobre escultura romana en Hispania (Tarragona, 1995), Tarragona, 1996, pp. 95. 108, donde se recoge toda la bibljografía sobre la cuestión. T. NOGALES BASARRATE: “Programas iconográficos del Foro de Mérida: el Templo de Diana", en Actas de la II Reunión sobre escultura romana en Hispania (Tarragona, 1995), Tarragona, 1996, pp. 115-134, que aporta la principal bibliogratía para aproximarnos al tema.

${ }^{7}$ J.L. de la BARRERA ANTÓN: "Nuevas aportaciones al estudio y configuración del programa iconográfico del Pórtico del Foro de Augusta Emerita", en Actas de la ll Reunión sobre escuitura romana en Hispania (Tarragona, 1995), Tarragona, 1996, pp. 109-113.

${ }_{28}$ No podemos finalizar este trabajo sin agradecer la colaboración que hemos recibido de distintas personas e instituciones para poder realizario. En primer lugar a J.M. ${ }^{2}$ Álvarez y T. Nogales, del Museo Nacional de Arte Romano de Mérida, que amablemente nos dieron a conocer la pieza con el relieve del toro y los pormenores de todo el relieve; a nuestro admirado amigo $\mathrm{M}$. Blech, del Instituto Arqueológico Alemán, de Madrid, por sus interesantes sugerencias y abrirnos las puertas de la fundamental biblioteca y completo archivo fotográfico de su institución. 